\title{
Physio-chemical treatment technologies for chromium removal
}

\author{
Yuhua Zhang ${ }^{1, a}$, Li Wei²,b \\ ${ }^{1}$ Guangzhou HKUST Fok Ying Tung Research Institute, Guangzhou, China \\ ${ }^{2}$ Department of Civil and Environmental Engineering, The Hong Kong University of Science and \\ Technology, Clear Water Bay, Kowloon, Hong Kong, China \\ ayuhuazhang@ust.hk, bweilihkust@ust.hk
}

\begin{abstract}
Keywords: Chromium removal; Photocatalytic reduction; Membrane electrolysis; Adsorption; Nanotechnology;
\end{abstract}

\begin{abstract}
The article reviews the technical applicability of various physio-chemical treatments for the removal of hexavalent chromium $(\mathrm{Cr}(\mathrm{VI}))$ from aqueous solution. A particular focus is given to membrane electrolysis, photocatalytic reduction, adsorption and the application of nanotechnology in $\mathrm{Cr}$ (VI) removal. About 50 published studies (2011-2017) are reviewed. Liquid membrane and electrodialysis were combined. Metal-organic frameworks (MOFs) emerged to enhance photocatalytic reduction. It is evident that adsorption is the most frequently studied and widely applied for the treatment of $\mathrm{Cr}(\mathrm{VI})$. And nanotechnology is mainly applied to nanoadsorbent which exhibited both reduction and adsorption capabilities. In general, further researches on methods with cost-effectiveness, technical-applicability, and plant-simplicity are vital for heavy metal removal such as chromium.
\end{abstract}

\section{Introduction}

Chromium ( $\mathrm{Cr}$ ) and its compounds widely used in diverse industrial processes, including alloys and steel manufacturing, metal finishing, electroplating, leather tanning, cooling tower blowdown, or pigments synthesis and dyeing [1]. Most chromium compounds usually start from sodium dichromate or chromate, either directly or indirectly through intermediate steps ${ }^{[2]}$. In aquatic systems, chromium exists as trivalent ( $\mathrm{Cr}(\mathrm{III}))$ and hexavalent $(\mathrm{Cr}(\mathrm{VI}))^{[3]}$. Chromium released to the environment poses serious threat to human health ${ }^{[4,5]}$ due to their carcinogenic and toxicological effects ${ }^{[5]}$. The toxicity highly depends on its oxidation forms ${ }^{[3]} \cdot \mathrm{Cr}(\mathrm{III})$ is about 300 times less toxic than $\mathrm{Cr}(\mathrm{VI})$ that is relatively stable and innocuous ${ }^{[6]}$. Chromium is considered as important priority pollutant worldwide ${ }^{[5]}$. The US Environment Protection Agency (EPA) recommended maximum drinking water level of chromium $(0.1 \mathrm{mg} / \mathrm{L})^{[1]}$. The World Health Organization $(\mathrm{WHO})$ and the Ministry of Health of China have set the permissible guideline of $0.05 \mathrm{mg} / \mathrm{L}$ for $\mathrm{Cr}(\mathrm{VI})$ in drinking water ${ }^{[5]}$.

Raising concerns regarding chromium have promoted the researches on chromium removal technologies. Conventional techniques that have been utilized to remove chromium include chemical precipitation, ion exchange, adsorption, membrane, and so on ${ }^{[7]}$. Chemical precipitation is the most widely used methods. Usually, the precipitation processes make use of hydroxide, sulfide, carbonate and phosphate resulting in Cr-solid state. However, it raised a disposal problem about the sludge ${ }^{[8]}$. Ion exchange is considered a better alternative, but not appealing because of high operational cost ${ }^{[8]}$. Compared with others, adsorption is cost effective, easy handling, flexible and selective. To maximize its advantages, researchers show keen interest in low cost adsorbents with 
high surface areas and adsorption capacities ${ }^{[1,9]}$. The increasingly mature nanotechnology promote the application of nanoadsorbent which enhances chemical reactivity and adsorbate/adsorbent interactions ${ }^{[1]}$. One the other hand, various kinds of nanomaterial also enhance the $\mathrm{Cr}(\mathrm{VI})$ reduction activity like $\mathrm{TiO}_{2}$ nanoparticles for photocatalytic reduction ${ }^{[10,11]}$. This article mainly showed newly

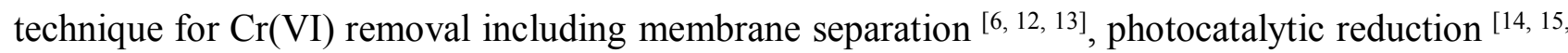
${ }^{16]}$, adsorption [17, 18, 19], and application of nanotechnology ${ }^{[20,21]}$.

\section{Membrane methods}

Membrane methods like ultrafiltration, nanofiltration, reverse osmosis, electrodialysis, and liquid membranes are alternative tools for better separation of $\mathrm{Cr}$ from wastewater. Sadyrbaeva proposed a novel hybrid process of galvanostatic electrodialysis and liquid membrane extraction for $\mathrm{Cr}(\mathrm{VI})$ removal from aqueous solutions ${ }^{[12]}$. The bulk liquid membrane contained solutions of tri-n-octylamine with admixtures of di(2-ehylhexyl) phosphoric acid in 1,2-dichloroethane and was found to be effective for single-stage removal. Besides, it was demonstrated that $\mathrm{Cr}$ could be extracted from $\mathrm{HCl}$ solutions into dilute solutions of hydrochloric, sulphuric, perchloric, phosphoric acids and water. Optimal conditions of varying ratio of the current, time and concentration are also determined in result of practically complete (>99.5\%) removal of $\mathrm{Cr}(\mathrm{VI})$ from the feed solution and a maximal stripping degree of $\sim 90 \%$ during $1.0-4$.0h of electrodialysis ${ }^{[12]}$. Instead, Kaya et. al. employed polymer inclusion membrane under constant electric current for the removal of $\mathrm{Cr}(\mathrm{VI})$ from water, which showed excellent selective and long-term use feature and high reproducibility of electric membrane extraction. Besides, polymer inclusion membrane was more stable than the supported liquid membrane. In this study, the $\mathrm{Cr}(\mathrm{VI})$ transport was achieved $98.33 \%$ after $40 \mathrm{~min}$ under optimized conditions ${ }^{[13]}$. Unlike electric membrane extraction, membrane distillation is a thermally driven process and also suitable alternatives to the conventional membrane methods ${ }^{[6]}$. Bhattacharya et. al. set up a modified coupled Knudsen and Poiseuille flow models for the coutercurrent direct contact membrane distillation. Hydrophobic polytetrafluoroethylene (PTFE) microporous membrane with polyethylene terephthalate (PET) showed good performance in the experiments. Also, the predictions exhibited good agreement with the experimental results ${ }^{[6]}$.

\section{Photocatalytic reduction}

As $\mathrm{Cr}(\mathrm{III})$ is much less toxic than $\mathrm{Cr}(\mathrm{VI})$ and can be easily precipitated and removed as a solid state, reduction of $\mathrm{Cr}(\mathrm{VI})$ to $\mathrm{Cr}(\mathrm{III})$ are of great important in effective remediation of $\mathrm{Cr}(\mathrm{VI})$-contaminated wastewater ${ }^{[10]}$. Electro-reduction, chemical reduction, and micro-reduction are commonly used, while photocatalytic reduction emerged with more effective and low-cost property, as well as no producing any hazardous chemicals [11]. Generally, semiconductor photocatalyst $\mathrm{TiO}_{2}$ was used due to its durability, low cost, low toxicity, superhydrophilicity, and remarkable chemical and photochemical stability ${ }^{[11]} . \mathrm{TiO}_{2}$ structures are classified into several forms: nanoparticles, microspheres, nanrods, and nanosheets ${ }^{[14,15,16]}$. And the $\mathrm{TiO}_{2}$ hollow sphere structure has raised considerable attention because of its low density, large surface area, good surface permeability, and great light-harvesting capacity. As the cavity sizes in the hollow shpere determine the photocatalytic reactivity and efficiency to a great extent, Cai et. al. studied the controllable size of $\mathrm{TiO}_{2}(356 \mathrm{~nm}, 440 \mathrm{~nm}, 587 \mathrm{~nm})$. Results showed that, after irradiation for $2 \mathrm{~h}$, the photo-reduction rate of $\mathrm{Cr}(\mathrm{VI})(\mathrm{pH}=2.82)$ for $\mathrm{TiO}_{2}(450 \mathrm{~nm})$ was $96 \%$, exhibiting an increase of $5 \%$ and $8 \%$ compared with $\mathrm{TiO}_{2}(370 \mathrm{~nm})$ and $\mathrm{TiO}_{2}(600 \mathrm{~nm})^{[22]}$. Ananpattarachai et. al. synthesized a novel bio-catalyst by adding $\mathrm{TiO}_{2}$ in chitosan/xylan with both adsorption and reduction capacity 
under ultraviolet irradiation, which achieved photocatalytic reduction rate of $\mathrm{Cr}(\mathrm{VI})$ at $0.56 \times 10^{3}$ ppm-min ${ }^{[23]}$. Li combined graphene and $\mathrm{TiO}_{2}$ nanospheres to facilitate photocatalytic reduction of Cr(VI) under UV irradiation ${ }^{[24]}$.

However, Wang et. al. pointed out that the application of $\mathrm{TiO}_{2}$ is limited due to its disadvantages like low photocurrent quantum yield, low solar energy utilization efficiency, difficult post-separation after treatment, and agglomeration. Great efforts have been devoted to searching for new visible-light active photocatalysts. Metal-organic frameworks (MOFs), a newly emerged type of functional inorganic-organic hybrid materials, were sought. MOFs can facilitate the fast transport and good accommodation of targeted molecules due to their desirable topology and high surface area ${ }^{[25]}$. Especially, the MOFs' band gap is closely related to the HOMO-LUMO gap, and energy transfer can take place from the organic linker to the metal-oxo cluster within some MOFs under light irradiation ${ }^{[26]}$, which can be further tuned to achieve efficient light harvest via rational modification of the inorganic unit or organic linkers ${ }^{[27]}$. In previous researches, some typical MOFs (or their composites) were employed as photocatalysts for the reduction of $\mathrm{Cr}(\mathrm{VI})$ under visible light irradiation, including MIL-101(Fe),ZnO@ZIF-8, Pd@UiO-66(NH $\left.\mathrm{N}_{2}\right)$, HPMo@MIL-100(Fe) and so on, with excellent reduction efficiency $(100 \%)^{[11]}$.

\section{Adsorption}

Adsorption is always attractive and the most promissing for $\mathrm{Cr}$ removal though generating non negligible amounts of sludge. To date, a variety of materials have been tried as adsorbents for $\mathrm{Cr}$ (VI) removal. The newly modified adsorbents were usually characterized by Fourier-transform infrared spectrophotometer (FTIR), scanning electron microscopic analysis (SEM) [18, 19], transmission electron microscopy (TEM) and X-ray diffraction (XRD) ${ }^{[28]}$. Besides, pseudo-second-order kinetic model and Langmuir isotherm model provided better correlation for the adsorption of $\mathrm{Cr}$ on the studied adsorbents ${ }^{[17,18,19]}$.

The raw material of adsorbent varies including organic, inorganic and also their combination. Polyanline (PANI) coated magnetic $\mathrm{Fe}_{3} \mathrm{O}_{4}$, carbon fabric and cellulose composites was found to improve both the removal rates and removal capacity of $\mathrm{Cr}(\mathrm{VI})^{[17]}$. Lee et. al. applied $\mathrm{Fe}_{2} \mathrm{O}_{3}$-carbon foam for $\mathrm{Cr}$ removal, which exhibited $6.7 \mathrm{mg} / \mathrm{g}$ adsorption capacity [29]. Mesoporous carbon microspheres (MCMs) possessed excellent adsorption capacity for $\mathrm{Cr}$ at as high as $165.3 \mathrm{mg} / \mathrm{L}$, while $\mathrm{Fe}_{3} \mathrm{O}_{4}$-loaded MCMs was at $156.3 \mathrm{mg} / \mathrm{L}$. What is more, $\mathrm{Fe}_{3} \mathrm{O}_{4}$-loaded $\mathrm{MCMs}$ had a good regeneration ability with a capacity of $123.9 \mathrm{mg} / \mathrm{L}$ for the fifth adsorption-desorption cycle ${ }^{[30]}$.

As biomass waste are discarded in large amount and have potential absorption capacity at low cost, researchers spend time in studying their Cr-removal efficiency. The biosorbent from modified Litchi peel showed maximum adsorption at $9.55 \mathrm{mg} / \mathrm{g}$ at $303 \mathrm{~K}^{[31]}$. Acrylonitrile grafted banana peels greatly improve the adsorption capacity at $96 \%$. The optimum conditions for adsorption of $\operatorname{Cr}(\mathrm{VI})$ was $\mathrm{pH} \mathrm{3}$, adsorbent dose $4 \mathrm{~g} / \mathrm{L}$, concentration $400 \mathrm{mg} / \mathrm{L}$ and contact time of $120 \mathrm{~min}{ }^{[32]}$. Results also showed that removing of peptic and viscous compounds, and the incorporation of a side chain $\left(-\mathrm{CH}_{2}-\mathrm{CH}-\mathrm{C}=\mathrm{N}\right)$ play crucial role in the enhancement of removal capacity ${ }^{[32]}$. Groundnut hull was also considered as potential biosorbent in Owalude's study [33]. Chitosan with quaternary ammonium groups was the other kind of biosorbent with excellent adsorption capacity at $39.1 \mathrm{mg} / \mathrm{L}$ ${ }^{[34]}$. Amine and quaternary ammonium groups are considered to be the main sites for sorption through electrostatic interaction, ionexchange, or a combination of these two mechanism ${ }^{[35]}$. Chug 
even found that extracellular polymeric substances (EPS) produced by two bacteria Azotobacter beifreinckii and Bacilus subtilis coulud remove $\mathrm{Cr}(\mathrm{VI})$ from aqueous system. In the adsorption process, carboxyl and phosphate groups were involved ${ }^{[36]}$.

A breakthrough in the field is the resort to adsorbents with both reductive and sorption properties in a single solid ${ }^{[4]}$. Zaitseva et. al. synthesized a bi-functional silica adsorbents for $\mathrm{Cr}$ (VI) reduction by thiol groups ( $\mathrm{SH})$ and subsequent complexation of $\mathrm{Cr}(\mathrm{III})$ by ethylenediaminetriacetate groups (ED3A). The most appropriate $\mathrm{pH}$ range was 1-3 and good $\mathrm{Cr}$ removal performance was observed in the presence of interference like ionic strength and other heavy metals ${ }^{[4]}$. Kuppusamy confirmed that the utilization of dried twigs of Melaleuca diosmifolia without pretreatment can detoxify and remove $\mathrm{Cr}(\mathrm{VI})$. This biosorbent constituted high concentrations of reducing compounds for $\mathrm{Cr}(\mathrm{VI})$ reduction. Especially, this biosorbent can treat $\mathrm{Cr}(\mathrm{VI})$ at wide-ranging $\mathrm{pH}(2-10)$ and temperature $\left(24-48^{\circ} \mathrm{C}\right)$ with high removal efficiency ${ }^{[18]}$. In Fellenz's study, the amino-functionalized MCM-41 sorbents exhibited both adsorption and reduction ability. The partially reduction theory was proposed that a proton released from the solid surface to the solution, afterwards, $\mathrm{Cr}$ (III) was

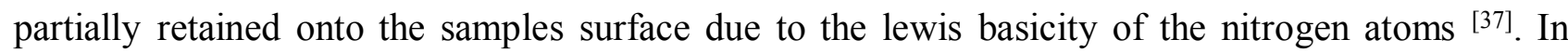
Zhu's research, Nitrogen and Fe(III) were co-doped in chitosan to improve the amphoteric adsorption performance. Interestingly, as coexistent $\mathrm{Cu}(\mathrm{II})$ and $\mathrm{Cr}(\mathrm{VI})$, it was found that $\mathrm{Cr}(\mathrm{VI})$ induced $\mathrm{H}^{+}$consumption and shielding effect to improve $\mathrm{Cu}(\mathrm{II})$ adsorption, while $\mathrm{Cu}$ (II) attracted $\mathrm{Cr}(\mathrm{VI})$ as cation-bridge and replace $\mathrm{H}^{+}$to enhance $\mathrm{Cr}(\mathrm{VI})$ redox ${ }^{[38]}$.

\section{Application of nanotechnology}

$\mathrm{TiO}_{2}, \mathrm{ZnO}, \mathrm{Fe}_{3} \mathrm{O}_{4}$ and zero-valent iron are most widely used in $\mathrm{Cr}(\mathrm{VI})$ removal in aqueous solution. The application of nanotechnology also enhance the $\mathrm{Cr}(\mathrm{VI})$ removal performance . Compared with traditional $\mathrm{TiO}_{2}$, Chen et. al. synthsized a highly reductive $\mathrm{TiO}_{2}$ nanocrystals on which diethylene glycol (DEG) chemically bonded. The newly synthesized $\mathrm{TiO}_{2}$ catalyst possessed a strong internal hole-scavenging effect and a high electron-releasing capacity. Besides, it had a good longevity for multiple use ${ }^{[20]}$. Deng et. al. successfully prepared a phosphorus doped porous ultrathin carbon nitride nanosheets (PCN-S) for $\mathrm{Cr}(\mathrm{VI})$ removal. Results showed that large specific surface areas from the porous nanosheet structure provided quantities of active sites for the photocatalyltic reaction. As for the low solar energy utilization efficiency of traditional $\mathrm{TiO}_{2}$, visible-light-driven (VLD) $\mathrm{CoO}_{\mathrm{x}}$ loaded $\mathrm{TiO}_{2}$-based nanosheets (Co-TNSs) with surface-enrich $\mathrm{CoO}_{\mathrm{x}}$ nanoparticles were synthesized with success. It was found that loaded $\mathrm{CoO}_{x}$ nanoparticles considerably enhance the visible-light (VL) absorption and a red-shift of the band gap of the TNSs. Also, the appropriate amount of $\mathrm{CoO}_{\mathrm{x}}(2.5$ at.\%) loading can effectively inhibit the recombination of photo-generated electron-hole pairs, thus improve the separation efficiency of charge carriers ${ }^{[16]}$.

The application of zero-valent iron nanoparticles in $\mathrm{Cr}(\mathrm{VI})$ removal is mainly on the basis of reduction from $\mathrm{Cr}(\mathrm{VI})$ to $\mathrm{Cr}(\mathrm{III})$. In Yu's case, it was found that higher $\mathrm{pH}$ values resulted in higher $\mathrm{Cr}(\mathrm{VI})$ removal efficiencies, which was because more $\mathrm{OH}^{-}$ions were generated when more $\mathrm{Cr}(\mathrm{VI})$ was reduced to $\mathrm{Cr}$ (III) by the nano zero-valent (nZVI) iron particle [21]. As the efficiency of zero-valent iron nanoparticles (ZVINs) for the $\mathrm{Cr}$ (VI) removal was strongly decrease due to particle agglomeration, Esfahani et. al. made a sepiolite-stablized ZVIN composite to solve this problem. They found that the removal efficiency increased in acidic and neutral $\mathrm{pH}$ conditions, while it considerably decreased by increasing the $\mathrm{Cr}(\mathrm{VI})$ concentration ${ }^{[9]}$. Fu et. al. also newly synthesized a humus-supported nanoscale zero-valent (H-NZVI) with both concurrent physical adsorption and 
chemical reduction for $\mathrm{Cr}(\mathrm{VI})$ removal. It was showed that supported NZVI in humus has succeeded in preventing aggregation and oxidation ${ }^{[39]}$. Also, the presence of bentonite could decrease the aggregation of nZVI and increase its reactivity ${ }^{[40,41]}$.

Compared with other $\mathrm{Cr}(\mathrm{VI})$ removal techniques, adsorption is often superior since it it cost effective, easy handling, flexible and selective. They can also be stripped and recycled. Researcher still showed keen interest in improved and advanced adsorbents with high surface areas and sorption capacities ${ }^{[1]}$. Nanosorbents are sought in forms of particle, sphere, sheet, tube, fiber and composite. The $\mathrm{Cr}(\mathrm{VI})$ adsorption capacity of various newly nanoadsorbent are shown in Table1. In the nanoadsorbnet studies, solution $\mathrm{pH}$, contact time, adsorbent dose and initial metal concentration were investigated. It was found that initial concentration has only a very little effect on adsorption ${ }^{[42]}$. With increase in $\mathrm{pH}$, the removal efficiency decreases, as the surface of magnetite nanoparticles become more negatively charged, resulting from repulsion between $\mathrm{Cr}(\mathrm{VI})$ and magnetite nanoparticles. The adsorbent dosage increases can enhance the removal efficiency to the maximum, however, it decrease afterwards also with the existence of aggregation ${ }^{[42]}$. Regarding to the effect of time, the removal efficiency increased to the maximum and reach equilibrium ${ }^{[42]}$. Talreja et. al. used the Fe nanoparticle (NP)-containing carbon nanofibers (CNFs) grown on porous carbon microbeads $(\sim 0.5 \mathrm{~mm})$ as adsorbent. Differently, Cr-laden wastewater could be effectively treated with this nanoadsorbent without adjusting the $\mathrm{pH}$ in a pretreatment step. The methanism of the removal was suggested to be both physisorption and electrostatic interactions ${ }^{[43]}$. Desorption and reuse of the nanoadsorbent is of great important. Rajput et. al. stripped the nanoparticles with $20 \mathrm{~mL}$ of $0.01 \mathrm{M} \mathrm{NaOH}$ by agitating at $25^{\circ} \mathrm{C}$ for $30 \mathrm{~min}$. The percent desorption was $\sim 44 \%{ }^{[1]}$. Choudhury et. al. regenerated nanoadsorbent using $50 \mathrm{ml} 0.1 \mathrm{M} \mathrm{NaOH}$ by stirring $90 \mathrm{~min}$, and finally obtained maximum $75 \%$ desorption. Increasing desorption cycle resulted in lack of active sites and them decrease the performance of nanocomposite. But after $4^{\text {th }}$ sorption cycle, it showed significant removal efficiency of $60 \%{ }^{[44]}$. Chitosan-1,2-Cyclohexylenedinitrilotetraacetic acid - graphene oxide (Cs/CDTA/GO) could be regenerated more than three times based on its adsorption/desorption cycles. After that, the removal efficiency was more than $95 \%{ }^{[45]}$. For the threonine doped polypyrrole nanocomposite, the removal efficiency remains unchanged for the first four cycles and was above $97 \%$ but the removal efficiency was reduced to $69 \%$ and $40 \%$ in the following fifth and sixth cyclerespectively. 
Table 1 Langmuir adsorption capacities for $\mathrm{Cr}(\mathrm{VI})$ removal of various kinds of nanoadsorbent

\begin{tabular}{|l|l|c|}
\hline Nanoadsorbent & Adsorption capacity $[\mathrm{mg} / \mathrm{g}]$ & Reference \\
\hline Magnetite $\left(\mathrm{Fe}_{3} \mathrm{O}_{4}\right) \quad$ nanoparticles & $20.2\left(25^{\circ} \mathrm{C}\right)$ & 1 \\
& $26.8\left(35^{\circ} \mathrm{C}\right)$ & \\
\hline Mesoporous magnetite (Fe3O4) nanospheres & $34.87\left(45^{\circ} \mathrm{C}\right)$ & 46 \\
& $7.31\left(25^{\circ} \mathrm{C}\right)$ & \\
\hline Humus-supported nanoscale zero-valent iron & $8.90\left(45^{\circ} \mathrm{C}\right)$ & 39 \\
\hline Bentonite-supported nanoscale zero-valent iron & 40.4 & 41 \\
& $65(0.001 \mathrm{M}$ ionic strength) & \\
\hline Fe-growncarbon nanofibers containing porous & 41 & 43 \\
carbon microbeads & $66(0.05 \mathrm{M} \mathrm{ionic} \mathrm{strength)}$ & \\
\hline Biogenic iron based nanoparticles & $983.2 \mathrm{mg} \mathrm{Cr}(\mathrm{VI}) / \mathrm{g} \mathrm{Fe}$ & 47 \\
\hline Titania embedded dead yeast nanocomposite & 162.07 & 44 \\
\hline Carbon nanotubes supported by activated carbon & 9.0 & 49 \\
\hline Reticulated chitosan micro/nanoparticles & $68.9\left(25^{\circ} \mathrm{C}, \mathrm{pH} 4\right)$ & \\
\hline Chitosan & $12.4\left(25^{\circ} \mathrm{C}, \mathrm{pH} 2\right)$ & 49 \\
\hline Chitosan-CDTA-GO nanocomposite & $25\left(25^{\circ} \mathrm{C}, \mathrm{pH} 4\right)$ & 45 \\
\hline Threonine doped polypyrrole nanocomposite & 166.98 & 50 \\
\hline
\end{tabular}

\section{Conclusions}

Environmental regulations have become more stringent in the past two decades, requiring an improved quality of treated effluent. A wide range of treatment technologies such as chemical precipitation, coagulation-flocculation, ion exchange and membrane filtration, have been developed and widely used for $\mathrm{Cr}(\mathrm{VI})$ removal. To date, researchers showed greater interest in membrane electrolysis, photocatalytic reduction and adsorption. Nanotechnology as novel methods have integrated in photocatalytic reduction and adsorption by nanomaterial, and have made good progresses in cost-effective, technical-applicable, and plant-simple methods for $\mathrm{Cr}$ (VI) removal. Liquid membrane combined with electrodialysis is now in the progress. Photocatalytic reduction with $\mathrm{TiO}_{2}$ is popular, however, disadvantage like difficult post-separation after treatment, and agglomeration limit its application. Future work need to examine the separation of $\mathrm{TiO}_{2}$, e.g. by making the synthesized $\mathrm{TiO} 2$ catalyst magnetic and separating it by a magnetic field ${ }^{[049]}$. MOFs was found to be the alternative as photocatalyst. Adsorption was considered as the promissing method for removal. The adsorbents are made from natural and synthesized organic, inorganic and the combination of them in order to seek for a low-cost and effective adsorbent. Nanoadsorbents with large surface area are popular nowadays, but the agglomeration of nanoadsorbents still needs further study so as to enhance the removal efficiency, e.g. through coated with other material like humus and bentonite.

\section{Acknowledgements}

The authors gratefully acknowledge the support from the Guangzhou Municipal Science and Technology Planning Project (2016201604030066). 


\section{Reference}

[1] Rajput, S, P. C. Jr, and D. Mohan. Journal of Colloid \& Interface Science 468(2016):334-346.

[2] Panda, R. C., et al. Journal of Cleaner Production 112(2015):4854-4862.

[3] Sultana, Mar Yam, et al. International Biodeterioration \& Biodegradation 96(2014):181-190.

[4] Zaitseva, N, V. Zaitsev, and A. Walcarius. Journal of Hazardous Materials 250-251C.2(2013):454-461.

[5] XiaohongGuan, HaoranDong, JunMa, IC Lo. Journal of Environmental Sciences 23.3(2011):372-380.

[6] Bhattacharya, Madhubanti, et al. Journal of Membrane Science 450.2(2014):447-456.

[7] Kurniawan, Tonni Agustiono, et al. Chemical Engineering Journal 118.1-2(2006):83-98.

[8] Mohan, D, and P. C. Jr. Journal of Hazardous Materials 137.2(2006):762-811.

[9] Esfahani, Amirhosein Ramazanpour, et al. Journal of the Taiwan Institute of Chemical Engineers 49(2014):172-182.

[10]Xie, Bihuang, et al. Chemical Engineering Journal 308(2016):791-797.

[11] Wang, Chong Chen, et al. Applied Catalysis B Environmental 193(2016):198-216.

[12] Sadyrbaeva, T. Zh. Chemical Engineering \& Processing Process Intensification 99(2015):183-191.

[13]Kaya, A, C. Onac, and H. K. Alpoguz. Journal of Hazardous Materials 317(2016):1-7.

[14]Xie, Wanjie, et al. Journal of Photochemistry \& Photobiology A Chemistry 333(2016):165-173.

[15]Deng, Yaocheng, et al. Applied Catalysis B Environmental 203(2016):343-354.

[16]Lu, Dingze, et al. Applied Catalysis B Environmental 190(2016):44-65.

[17]Qiu, Bin, et al. Applied Surface Science 334(2014):7-14.

[18] Kuppusamy, Saranya, et al. Process Safety \& Environmental Protection 100(2016):173-182.

[19] Yi, Yunhong, et al. Journal of Molecular Liquids 225(2017):28-33.

[20]Chen, Gongde, et al. Water Research (2016).

[21] Yu, Ruey Fang, et al. Chemical Engineering Journal 255.6(2014):568-576.

[22] Cai, J., et al. Journal of colloid and interface science 490(2016).

[23] Ananpattarachai, Jirapat, and P. Kajitvichyanukul. Journal of Cleaner Production 130(2015):126-136.

[24]Li, Yao, et al. Applied Catalysis B Environmental 199(2016):412-423.

[25] Shi, Li, et al. Advanced Science 2.3(2015).

[26]Fuentescabrera, M, et al. Journal of Chemical Physics 123.12(2005):903-907.

[27] Shen, L., et al. Dalton Transactions 42.37(2013):13649-57.

[28] Stoicaguzun, A, et al. International Journal of Biological Macromolecules 91(2016):1062-1072. 
[29]Lee, C. G., et al. Chemosphere 166(2017):203-211.

[30]Zhou, J., et al. Journal of Colloid \& Interface Science 462.8(2016):200-207.

[31] Adamczuk, Agnieszka, and D. Kołodyńska. Chemical Engineering Journal 274(2015):200-212.

[32] Ali, Ashraf, K. Saeed, and F. Mabood. Alexandria Engineering Journal 55.3(2016):2933-2942.

[33] Owalude, Samson O., and A. C. Tella. Beni-Suef University Journal of Basic and Applied Sciences (2016).

[34]Hua, Chao, et al. Chinese Journal of Chemical Engineering (2016).

[35] Gao, Qianhong, et al. Radiation Physics \& Chemistry 130(2017):92-102.

[36]Chug, R, et al. Bioresource Technology 214(2016):604-608.

[37]Fellenz, Nicolás, et al. Microporous \& Mesoporous Materials 239(2017):138-146.

[38]Zhu, Changqing, et al. Chemical Engineering Journal 306(2016):579-587.

[39] Fu, Rongbing, et al. Separation \& Purification Technology (2016).

[40]Diao, Zeng Hui, et al. Chemical Engineering Journal 302(2016):213-222.

[41] Soliemanzadeh, Akbar, and M. Fekri. Microporous \& Mesoporous Materials 239(2017):60-69.

[42]Padmavathy, K. S., G. Madhu, and P. V. Haseena. Procedia Technology 24(2016):585-594.

[43] Talreja, Neetu, D. Kumar, and N. Verma. Journal of Water Process Engineering 3.1(2014):34-45.

[44] Choudhury, Piyali Roy, et al. Journal of Environmental Chemical Engineering 5(2017):214-221.

[45] Ali, Mohamed E. A. Arabian Journal of Chemistry (2016).

[46] Kumari, M, P. C. Jr, and D. Mohan. Journal of Colloid \& Interface Science 442(2015):120-132.

[47]Xiao, Zhengli, et al. Separation \& Purification Technology 174(2017):466-473.

[48]Atieh, Muataz Ali. Procedia Environmental Sciences 4.10(2011):281-293.

[49]Dima, Jimena Bernadette, C. Sequeiros, and N. E. Zaritzky. Chemosphere 141(2015):100-111.

[50] Amalraj, Augustine, et al. Journal of Water Process Engineering 13(2016):88-99. 